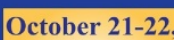 \\ 2021 TEX TEH X

\section{ELECTROSPINNING OF ANTIBACTERIAL POLYURETHANE/ZnO NANOFIBERS}

\section{DOI: 10.35530/TT.2021.29}

\author{
İ.Y. Mol*, F.C. Çallioğlu \\ Textile Engineering Department, Engineering Faculty, Süleyman Demirel University, Turkey \\ (E-mail: iremyagmurmol@gmail.com, fundacengiz@sdu.edu.tr)
}

\begin{abstract}
In this study, it is aimed to produce and characterize antibacterial polyurethane (PU)/Zinc oxide $(\mathrm{ZnO})$ nanofibers by electrospinning method. Firstly, polymer solutions were prepared at various $\mathrm{ZnO}$ concentrations such as $0,0.2,0.4,0.6,0.8,1$. Then solution properties (conductivity, viscosity, surface tension) were determined and analysed the effects of $\mathrm{ZnO}$ concentration on the solution properties. PU/ZnO nanofibers produced via electrospinning under the optimum process parameters (voltage, distance between electrodes, feed rate and atmospheric conditions). Finally, the nanofibers were characterized in terms of fibre morphology, thermal stability, permeability and antibacterial activity using SEM-EDS, DSC-TGA, water vapour permeability and disk diffusion methods. According to the solution results; it was observed that conductivity and surface tension decrease significantly with ZnO addition. On the other hand, solution viscosity increases as the $\mathrm{ZnO}$ concentration increases. From the SEM images, it has been seen clearly that average fibre diameter increases with $\mathrm{ZnO}$ concentration and incorporation of $\mathrm{ZnO}$ particles to the fibre structure was verified by SEM-EDS. According to the thermal analyse result, nanofibers begin to degrade between $271.94{ }^{\circ} \mathrm{C}$ and $298.73{ }^{\circ} \mathrm{C}$. In addition, water vapour permeability increases as the $\mathrm{ZnO}$ concentration increase. Lastly antibacterial activity against gram negative (E.coli) and gram positive (S. aureus) was determined with specific zone diameter.
\end{abstract}

Keywords: antibacterial, electrospinning, nanofiber, polyurethane, Zinc oxide

\section{INTRODUCTION}

Protective textiles are the materials to prevent the risk of exposure to harmful substances (virus, bacteria etc.) and bad environmental conditions, to protect them from this risk and/or to reduce this risk. Especially fibre structure, thermal, chemical, microbiological, pore size, air permeability, barrier etc. properties are important for this aim [1].

In recent years, various polymers can be easily electro spun to obtain advanced fibrous materials [2,3]. Among them, polyurethane based nanofibers are the most common and functional materials due to their high elasticity, good mechanical, protective and barrier properties. Polyurethane based nanofibers are especially used in medical, filtration, protective textiles, etc. [4-6]. Antibacterial nanofibers are also important for these application areas. In the literature, there are many studies about PU nanofibers containing various antibacterial agents $[7,8]$.

For this study, $\mathrm{ZnO}$ was chosen as an antibacterial agent because of its nontoxicity, compatibility with the skin, and its chemical stability when exposed to both high temperatures and UV [9]. There are some studies on $\mathrm{ZnO}$ based nanofibers in the literature. Lee studied PU/ZnO based nanofibers to obtain UV protective textile materials. $\mathrm{He}$ noted that very thin electro spun $\mathrm{ZnO}$ nanocomposite fibre layer significantly 
increased UV blocking for both the UV-A and UV-B ranges and exhibited excellent UV protection. In addition, it was observed that the UV protective properties increased with increasing $\mathrm{ZnO}$ concentrations [10]. $\mathrm{Wu}$ and Pan also prepared $\mathrm{ZnO}$ nanofibers by electrospinning. They found that the fibre diameter increased with $\mathrm{ZnO}$ content and the morphology of inorganic $\mathrm{ZnO}$ fibres was affected by the calcination time.

\section{MATERIALS AND METHODS}

In this study, polyurethane (PU) was used as a polymer, dimethylformamide (DMF) was used as a solvent and zinc oxide $(\mathrm{ZnO})$ was used as an additive to provide antibacterial activity. During the experimental studies, PU polymer concentration was kept constant at $15 \mathrm{wt} \%$ and this value was determined from our preliminary studies. Zinc oxide concentrations such as $0,0.2,0.4,0.6,0.8$ and $1 \mathrm{wt} \%$ were applied to the PU/DMF solutions. All solutions were prepared under the same conditions (mixing time, temperature, etc.).

First of all, solution properties such as conductivity, viscosity (shear rate $5 \mathrm{~s}^{-1}$ ) and surface tension were measured. Then, nanofiber production was carried out by electrospinning method under the optimum process parameters. During the spinning process, $24 \mathrm{kV}$ voltage, $0.2 \mathrm{ml} / \mathrm{h}$ solution feed rate and $22 \mathrm{~cm}$ distance between the electrodes were applied for all solutions. In addition, all nanofibers were produced under ambient conditions of $36 \pm 2 \%$ humidity and $23 \pm 2{ }^{\circ} \mathrm{C}$ temperature. All nanofibers were produced for 30 minutes and collected on an aluminium foil.

Nanofiber morphology such as fibre diameter, diameter uniformity and nanoweb surface structure were analysed by Scanning Electron Microscopy (SEM). Fibre diameter histograms were obtained from the SPSS program. The presence of $\mathrm{ZnO}$ was determined by EDS and the thermal behaviour of nanofibers was analysed by DSC and TGA. In addition, the water vapour permeability test was performed according to BS 7209, BS 3424 standards. Finally, antibacterial activity against gram negative (E. coli) and gram positive (S. aureus) was determined by disc diffusion method.

\section{RESULTS AND DISCUSSIONS}

Viscosity, conductivity and surface tension results of PU/DMF solutions with various $\mathrm{ZnO} \mathrm{wt} \%$ concentrations are given in table 1.

Table 1. Solution results of PU/DMF with various concentrations of $\mathrm{ZnO}$ wt \%

\begin{tabular}{|c|c|c|c|}
\hline Samples & $\begin{array}{c}\text { Viscosity (mPa.s) } \\
\left(\text { Shear rate: } \mathbf{5 ~ s}^{\mathbf{- 1}}\right)\end{array}$ & $\begin{array}{c}\text { Conductivity } \\
(\boldsymbol{\mu} \mathbf{S} / \mathbf{c m})\end{array}$ & $\begin{array}{c}\text { Surface Tension } \\
(\mathbf{m N} / \mathbf{m})\end{array}$ \\
\hline PU0 & 2240 & 5.16 & 36.4 \\
\hline PU0.2 & 3970 & 1.01 & 6.74 \\
\hline PU0.4 & 4570 & 0.93 & 7.63 \\
\hline PU0.6 & 5680 & 0.82 & 7.29 \\
\hline PU0.8 & 5080 & 1.17 & 6.77 \\
\hline PU1 & 7680 & 0.72 & 7.53 \\
\hline
\end{tabular}

Also figure 1 shows the changing of viscosity, conductivity and surface tension of $\mathrm{PU} / \mathrm{DMF}$ solutions with $\mathrm{ZnO}$ concentrations. 


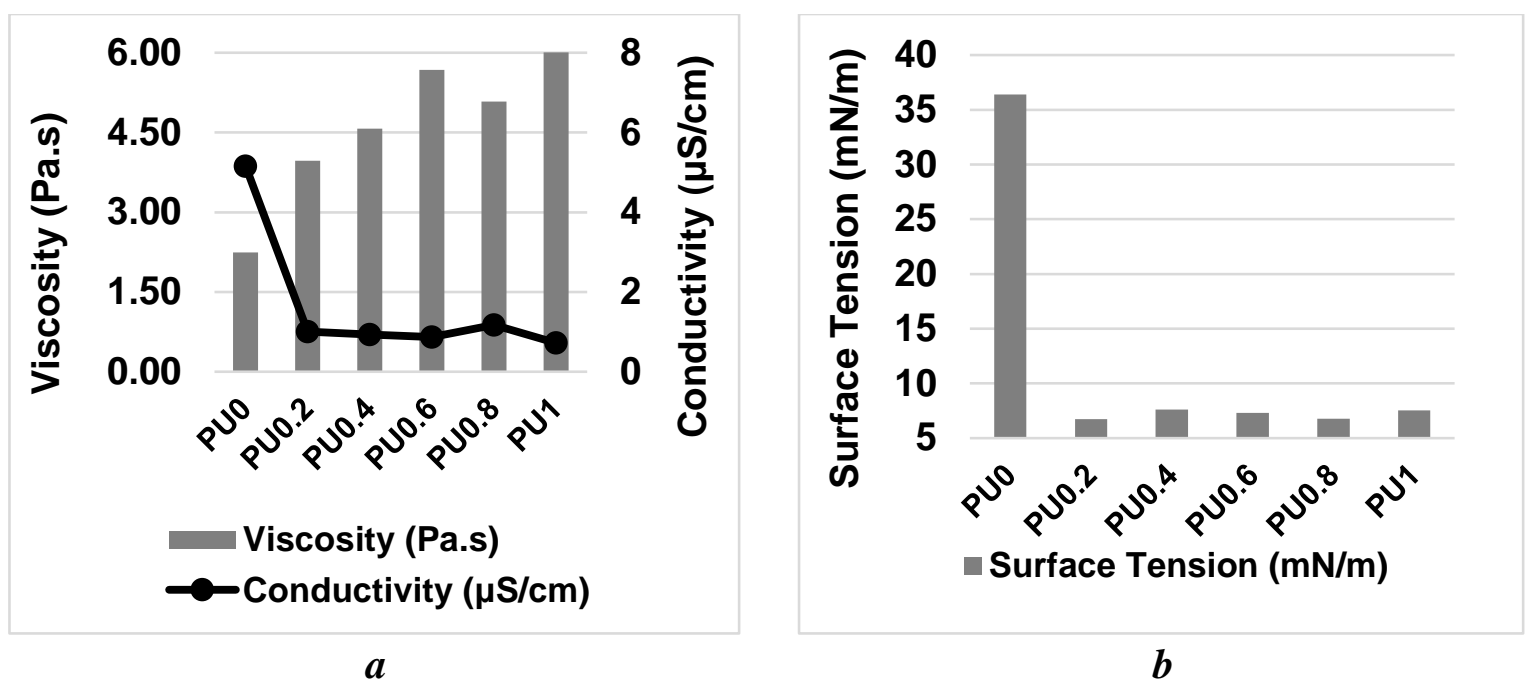

Figure 1. Graphical representation of: a - viscosity and conductivity of PU/ZnO solutions; b - surface tension of PU/ZnO solutions

It is clearly seen that from table 1 and figure 1 , solution viscosity increases with $\mathrm{ZnO}$ concentration while conductivity decreases. On the other hand, with the initial addition of $\mathrm{ZnO}$, conductivity and surface tension decreases significantly, but is not affected by the $\mathrm{ZnO}$ concentration increase. This result is compatible with literature [11]. Figure 2 shows the SEM images and histograms of PU/ZnO nano webs.

PU0
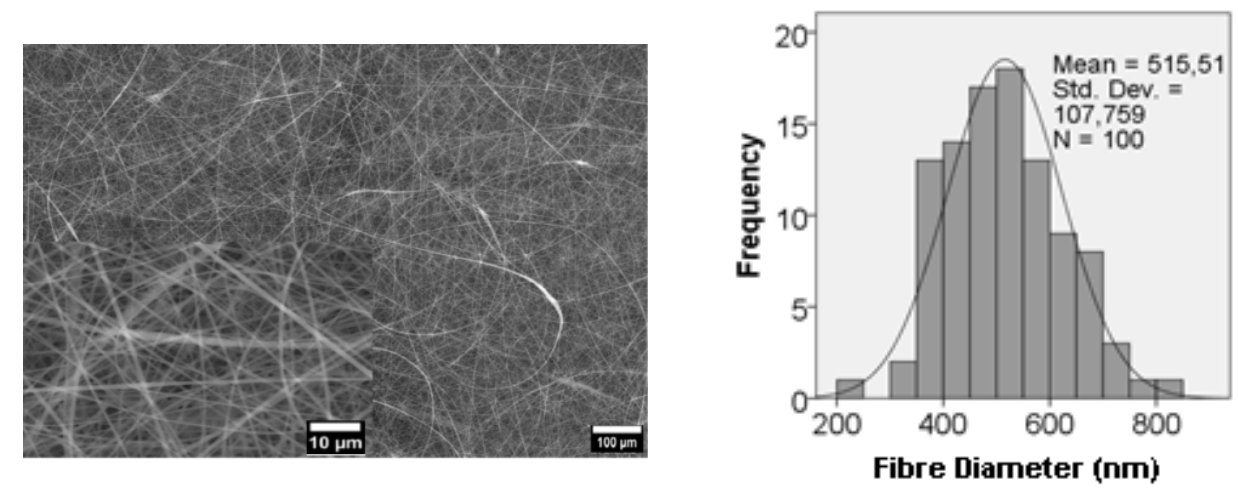

PU0.2
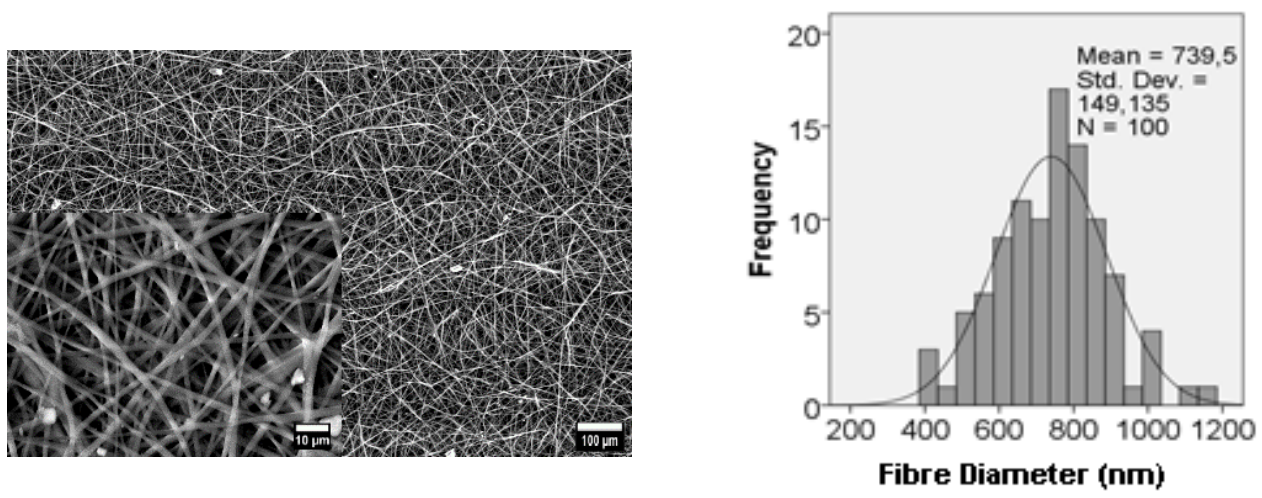
PU0.4
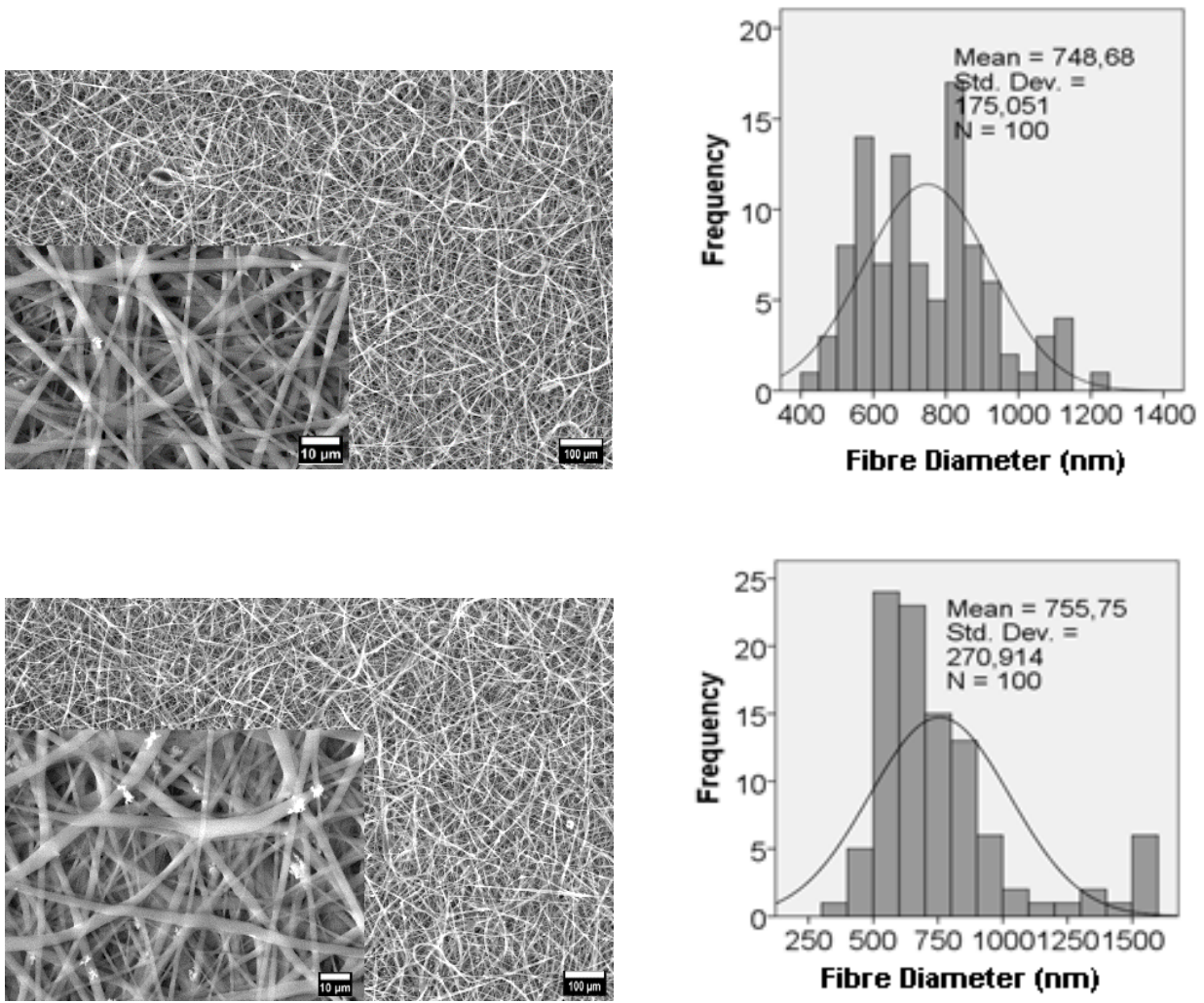

PU0.6
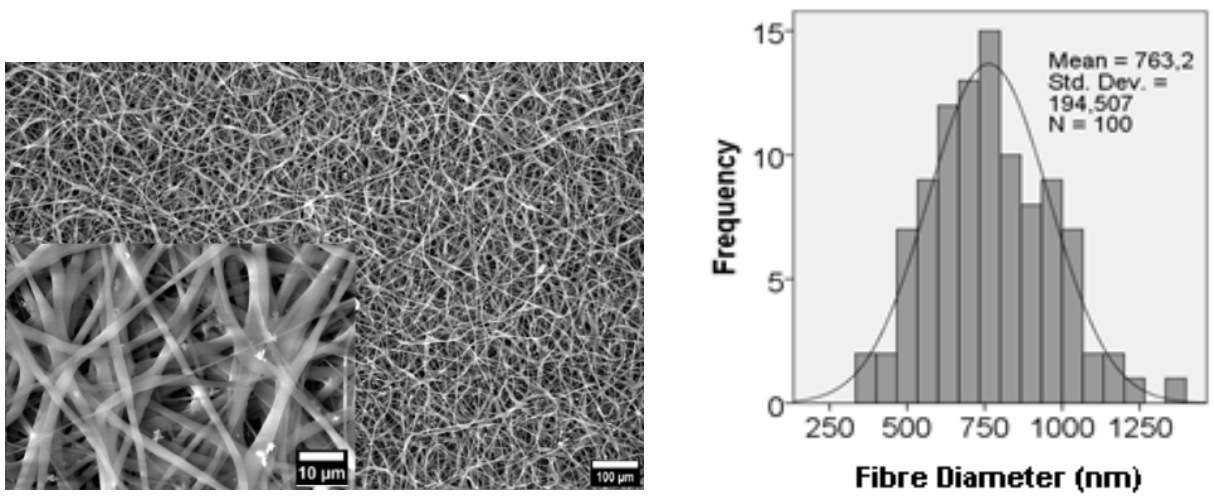

PU1
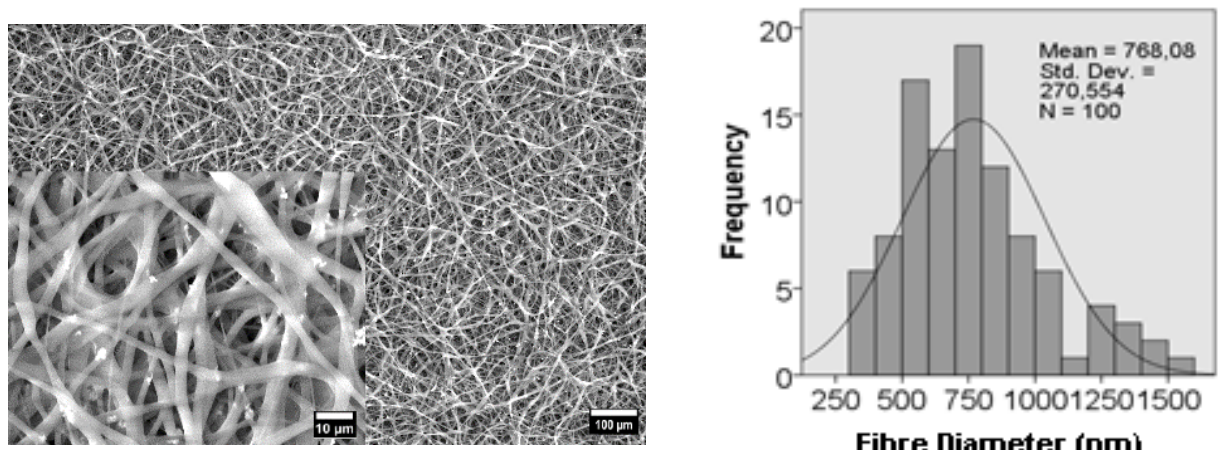

Figure 2. SEM images and fibre diameter histograms of PU/DMF nanofibers

From the SEM images, it was observed that the fibre diameter and stickiness increased with the addition of $\mathrm{ZnO}$. Average fibre diameter was calculated as $550 \mathrm{~nm}$ for PU/DMF without ZnO (PU0). On the other hand, average fibre diameter increased to approximately $750 \mathrm{~nm}$ with addition of various concentrations of $\mathrm{ZnO}$. It is clearly seen 
from the SEM images that incorporation of $\mathrm{ZnO}$ particles to the nanofibers were achieved successfully. Unimodal histogram curves were obtained from PU0, PU0.2, PU0.8 samples.

The changing of average fibre diameter and fibre diameter uniformity with $\mathrm{ZnO}$ concentration increase is shown in figure 3.

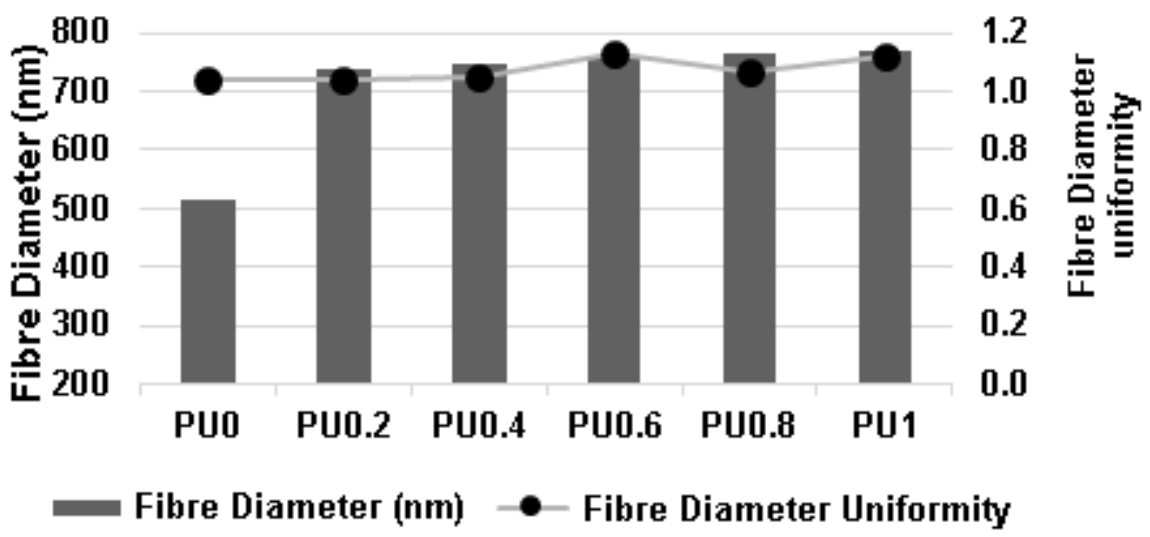

Figure 3. Average fibre diameter and diameter uniformity coefficient of PU/ZnO nanofibers

Figure 3 presents that average fibre diameter increased significantly with the first addition of $\mathrm{ZnO}$ to the PU nanofibers. Fibre diameter uniformity coefficient is not effected from $\mathrm{ZnO}$ concentration. It is possible to say that uniform $\mathrm{PU} / \mathrm{ZnO}$ nanofibers were obtained. From the water vapour permeability test results, it was determined that water vapour permeability increased with addition of $\mathrm{ZnO}$ (PU0: $2484.62 \mathrm{~g} / \mathrm{m}^{2} /$ day and PU0.8: $2910.28 \mathrm{~g} / \mathrm{m}^{2} /$ day).

$\mathrm{ZnO}$ particles can be seen clearly into the fibre structure and also $\mathrm{ZnO}$ existence was verified by SEM-EDS (figure 4).

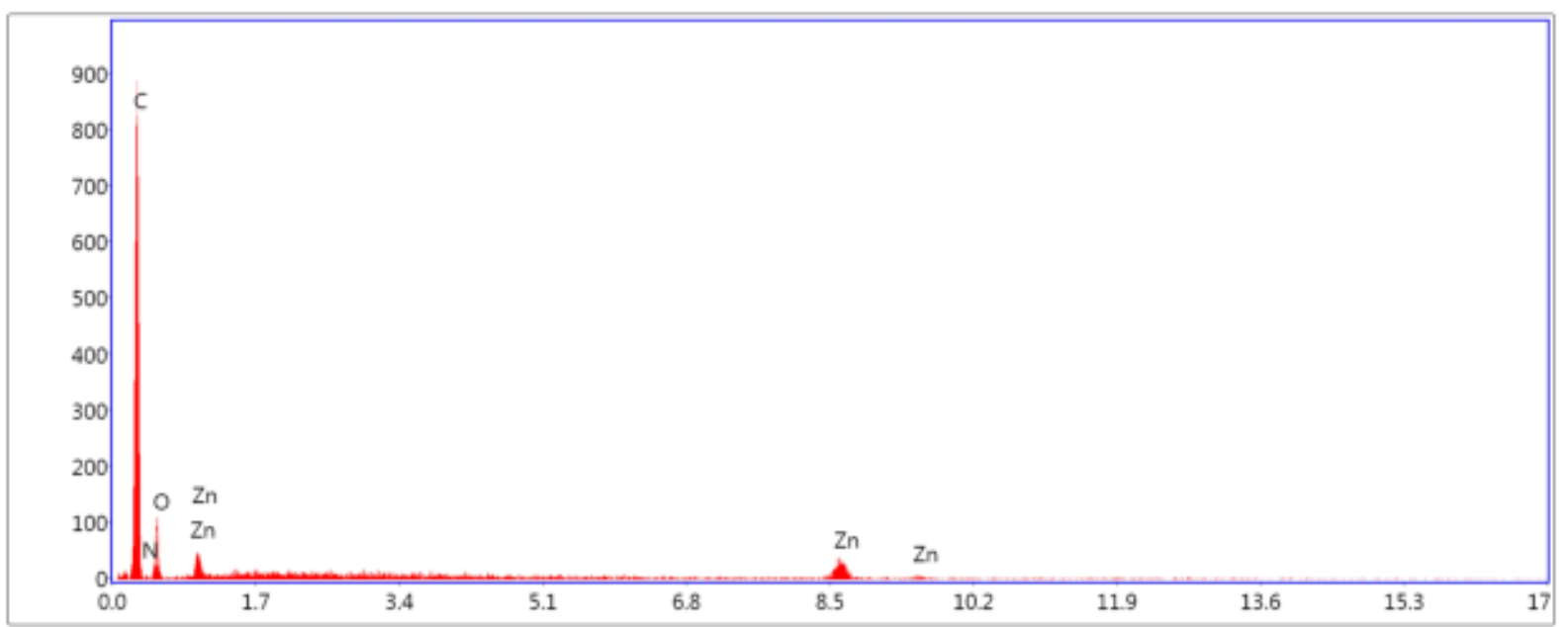

Figure 4. SEM-EDS Spectroscopy of PU nanofibers with 0.8 wt \% ZnO

Elemental analysis results of $\mathrm{Pu} / \mathrm{ZnO}$ nanofibers are given in table 2. Thermal behaviour of $\mathrm{Pu} / \mathrm{ZnO}$ nanofibers were analysed by DSC-TGA (figure 5, figure 6). 
Table 2. SEM-EDS results of PU/ZnO nanofiber samples

\begin{tabular}{|c|c|c|c|c|c|c|c|}
\hline $\begin{array}{c}\text { Sample } \\
\text { code }\end{array}$ & $\begin{array}{c}\mathbf{C} \\
\mathbf{( \% )}\end{array}$ & $\begin{array}{c}\mathbf{N} \\
\mathbf{( \% )}\end{array}$ & $\begin{array}{c}\mathbf{O} \\
\mathbf{( \% )}\end{array}$ & $\begin{array}{c}\mathbf{Z n} \\
\mathbf{( \% )}\end{array}$ & $\mathbf{M g} \mathbf{( \% )}$ & $\begin{array}{c}\text { Al } \\
\mathbf{( \% )}\end{array}$ & $\begin{array}{c}\text { Na } \\
\mathbf{( \% )}\end{array}$ \\
\hline PU0.2 & 68.13 & 7.20 & 19.95 & - & 0.27 & 3.89 & 0.55 \\
\hline PU0.4 & 75.76 & - & 23.25 & 0.99 & - & - & - \\
\hline PU0.6 & 76.41 & - & 21.02 & 1.38 & - & 1.19 & - \\
\hline PU0.8 & 70.87 & 6.57 & 20.22 & 2.34 & - & - & - \\
\hline PU1 & 70.63 & 7.28 & 20.01 & 2.07 & - & - & - \\
\hline
\end{tabular}

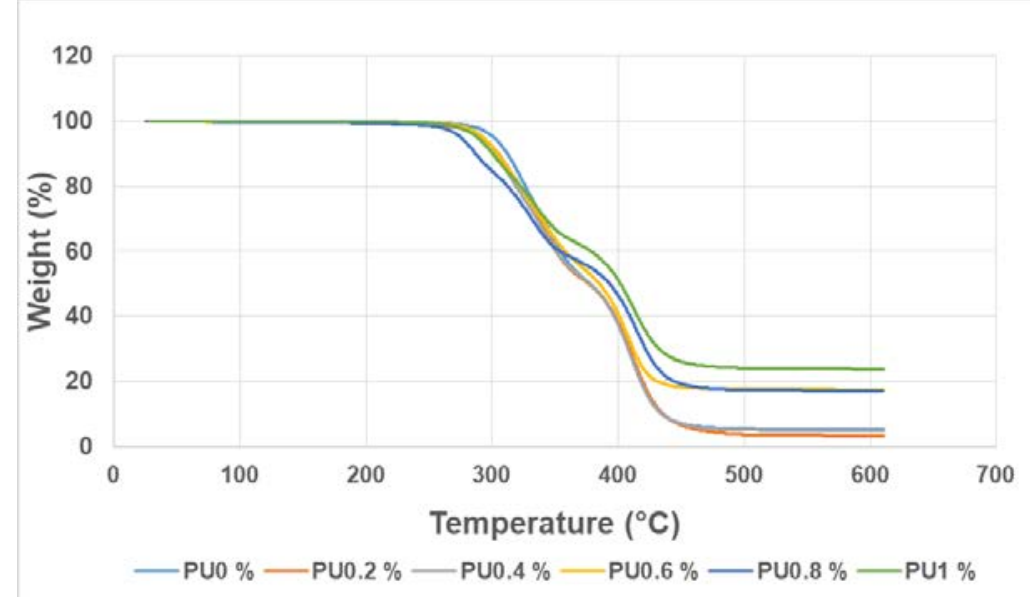

Figure 5. TGA analysis of PU nanofibers with various concentrations of $\mathrm{ZnO}$

As shown, the amount of $\mathrm{ZnO}$ is visibly changing the temperature of any thermal resistance value. The major mass loss for $\mathrm{PU} / \mathrm{ZnO}$ is around $275-280^{\circ}$. In the $\mathrm{PU} / \mathrm{ZnO}$ curve, after 430 degrees, PU1 \% containing the most zinc oxide remained the most residues and this ratio was 25\%. PU0, PU0.2 and PU0.4 left the least residues close to each other. This rate is $1 \%$.

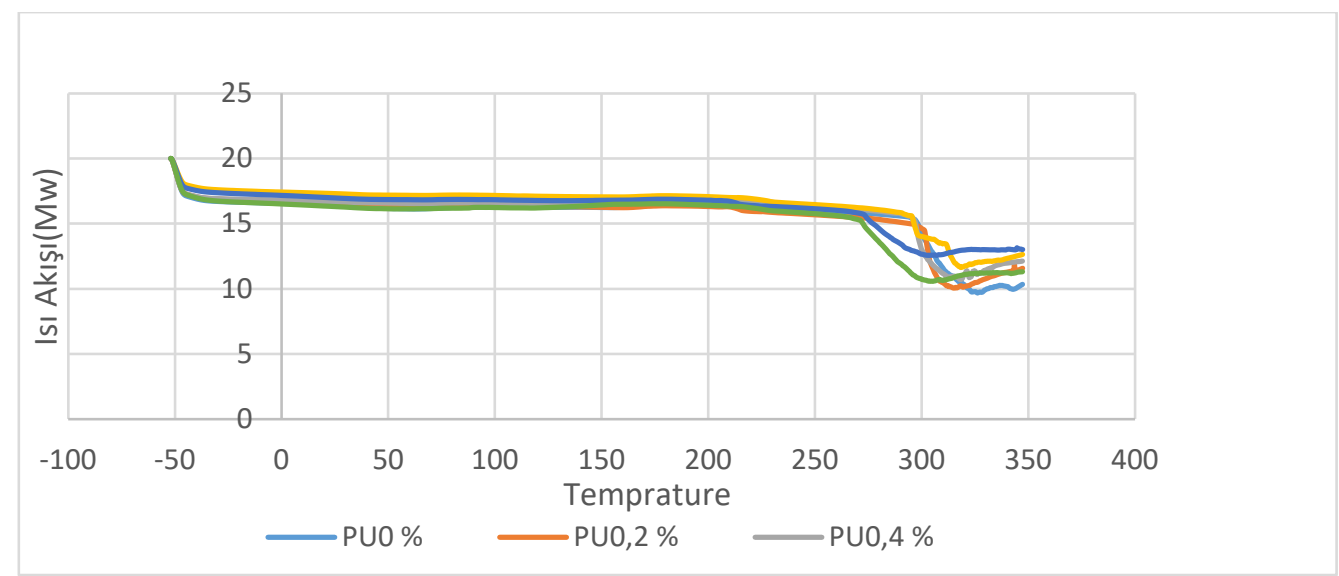

Figure 6. DSC analysis of PU nanofibers with various concentrations of $\mathrm{ZnO}$

Thermal characterization of polymers was investigated in nitrogen atmosphere using differential scanning calorimetry (DSC) and glass transition temperature (Tg) and melting temperature $(\mathrm{Tm})$ were determined. Analysis $-50^{\circ} \mathrm{C}$ to $350^{\circ} \mathrm{C}$ at a scan rate of $10^{\circ} \mathrm{C} / \mathrm{min}$ has been carried out. In general, the temperatures at which nanofibers begin to degrade are between $271.94^{\circ} \mathrm{C}$ and $298.73^{\circ} \mathrm{C}$. Similarly, the temperature at which the mass loss ends is close to each other and varies between $308.11^{\circ} \mathrm{C}$ and $330.90^{\circ} \mathrm{C}$. 
Lastly, antibacterial activity against gram negative (E.coli) and gram positive ( $S$. aureus) was determined with specific zone diameter for PU nanofibers with 0.8 wt \% $\mathrm{ZnO}$.

\section{CONCLUSION}

This study was carried out for the fabrication and characterization of antibacterial $\mathrm{PU} / \mathrm{ZnO}$ nanofiber surface with various $\mathrm{ZnO}$ concentrations by electrospinning. According to the solution results; viscosity increased with $\mathrm{ZnO}$ concentration while conductivity and surface tension decreased. In addition, average fibre diameter increased and fibre stickiness was observed with $\mathrm{ZnO}$ concentration increase. On the other hand, fibre diameter uniformity was not affected from $\mathrm{ZnO}$ addition. $\mathrm{ZnO}$ incorporation to the PU nanofibers was shown by SEM images and ZnO presence was verified via SEM-EDS. Also it was determined that water vapour permeability increased with $\mathrm{ZnO}$ addition. Thermal behaviour of PU nanofibers with various concentrations of $\mathrm{ZnO}$ was investigated by DSC-TGA analysis. Lastly, good antibacterial activity against gram negative (E. coli) and gram positive ( $S$. aureus) was determined.

\section{ACKNOWLEDGMENT}

The authors would like to express appreciation for the financial support of the Süleyman Demirel University Scientific Researches Project Unit [Project Number $=$ FYL2020-8206]. I would like to thank the Scientific and Technological Research Council of Turkey for their support to the 2247-C Trainee Researcher Scholarship Program (STAR) 2020/1.

\section{REFERENCES}

[1] Duran, K., Bahtiyari, M.İ., Atav, R., Protective nonwoven technical textiles, In: Textile and Apparel, 2007, 17, 3, 174-177, https://hdl.handle.net/11454/64515

[2] Huang, Z.M., Zhang, Y.Z., Kotaki, M., et al., A review on polymer nanofibers by electrospinning and their applications in nanocomposites, In: Compos. Sci. Technol., 2003, 63, 15, 2223-2253, https://doi.org/10.1016/S0266-3538(03)00178-7

[3] Mirjalili, M., Zohoori, S., Review for application of electrospinning and electrospun nanofibers technology in textile industry, In: J. Nanostructure. chem., 2016, 6, 3, 207-213, https://doi.org/10.1007/s40097-016-0189-y

[4] Gorji, M., Jeddi, A.A., Gharehaghaji, A.A., Fabrication and characterization of polyurethane electrospun nanofiber membranes for protective clothing applications, In: J. Appl. Polym. Sci., 2012, 125, 5, 4135-4141, https://doi.org/10.1002/app.36611

[5] Mohraz, M.H., Golbabaei, F., Yu, I.J., Mansournia, M.A., et. al., Preparation and optimization of multifunctional electrospun polyurethane/chitosan nanofibers for air pollution control applications, In: IJEST., 2019, 16, 2, 681-694, https://doi.org/10.1007/s13762-018-1649-3

[6] Akduman, C., Özgüney, I., Kumbasar, E.P.A., Preparation and characterization of naproxenloaded electrospun thermoplastic polyurethane nanofibers as a drug delivery system, In: Mater. Sci. Eng. C., 2016, 64, 383-390, https://doi.org/10.1016/j.msec.2016.04.005

[7] Jatoi, A.W., Polyurethane nanofibers incorporated with $\mathrm{ZnAg}$ composite nanoparticles for antibacterial wound dressing applications, In: Compos. Commun., 2020, 19, 103-107, https://doi.org/10.1016/j.coco.2020.03.004

[8] Lee, J.H., Park, S.H., Kim, S.H., Fabrication of bio-based polyurethane nanofibers incorporated with a triclosan/cyclodextrin complex for antibacterial applications, In: RSC. Adv., 2020, 10, 6, 34503458, https://doi.org/10.3390/polym13040576

[9] Yang, H., Zhu, S., Pan, N., Studying the mechanisms of titanium dioxide as ultraviolet-blocking additive for films and fabrics by an improved scheme, In: J. Appl. Polym. Sci., 2004, 92, 5, 3201-3210, 
https://doi.org/ 10.1002/app.20327

[10] Lee, S., Developing UV-protective textiles based on electrospun zinc oxide nanocomposite fibers, In: Fibers Polym., 2009, 10, 3, 295-301, https://doi.org/10.1007/s12221-009-0295-2

[11] Aydemir, E.H., Topical treatment (part two): Vehicles, nature and functions, In: Turkderm, 2012, 46, 4, 175, https://doi.org/ 10.4274/Turkderm.42275 